\title{
Erläuterungen zu der nebenstehenden Tabelle
}

In der ersten horizontalen Spalte der Tabelle bedeuten

1 Band

2 Literatur des Jahres

3 Anzahl der durchgesehenen Zeitschriften (Unsichere Angaben sind kursiv gesetzt)

4 Zahl der Mitarbeiter

5 Schriftleitung:

$$
\begin{aligned}
& \mathrm{W}=\mathrm{W} . \mathrm{F} . \text { Wislicenus }(1859-1905) \\
& \mathrm{B}=\mathrm{A} \text {. Berberich (1861-1920) } \\
& \mathrm{C}=\mathrm{F} \text {. Cohn (1866-1922) } \\
& \mathrm{N}=\mathrm{P} . \mathrm{V} . \text { Neugebauer }(1878-1940) \\
& \mathrm{H}=\mathbf{K} \text {. Heinemann }
\end{aligned}
$$

6 Anzahl der Teile

8 Seitenzahlen

9 Erscheinungsjahr

10 Preis in DM.

Die Bearbeitung der ersten sechs Bände geschah zunächst in Straßburg, von Band 7-11 in Berlin-Tempelhof. Ab Band 12 erfolgte die Bearbeitung am Astronomischen Rechen-Institut zu Berlin und von Band 44 an in Heidelberg.

Die horizontalen Linien in der Tabelle nach Band 11, 17, 23, 44, und 47 kennzeichnen den Utbergang von einer Gliederung des Stoffes im AJB zu einer revidierten. Bände mit gleichartigen Gliederungen liegen zwischen je zwei horizontalen Linien. 